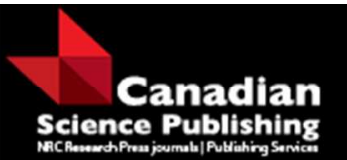

Canadian Journal of Forest Research Revue canadienne de recherche forestière

\title{
Exploring the linkages between multi-functional forestry goals and the legacy of spruce plantations in Scotland
}

\begin{tabular}{|r|l|}
\hline Journal: & Canadian Journal of Forest Research \\
\hline Manuscript ID & cjfr-2015-0399.R1 \\
\hline Manuscript Type: & Article \\
\hline Complete List of Authors: & $\begin{array}{l}\text { Nijnik, Maria; The James Hutton Institute, Social, Economic and } \\
\text { Geographical Sciences Group } \\
\text { Nijnik, Anatoliy; Environmental Network limited } \\
\text { Brown, Iain; The James Hutton Institute }\end{array}$ \\
\hline Keyword: & $\begin{array}{l}\text { ecosystem services, woodlands, stakeholders, attitudinal diversity, Q- } \\
\text { method }\end{array}$ \\
\hline & \\
\hline
\end{tabular}


Exploring the linkages between multi-functional forestry goals and the legacy of spruce plantations in Scotland

Maria Nijnik $^{1}$

The James Hutton Institute, Craigiebuckler, Aberdeen, AB15 8QH, UK, phone: +44 (0)1224 395305, fax: +44 (0) 844928 5429, E-mail: maria.nijnik@hutton.as.uk

\author{
Albert Nijnik \\ Environmental Network Ltd, Aboyne, UK, \\ E-mail: albertnijnik@yahoo.com
}

Iain Brown

The James Hutton Institute, Craigiebuckler, Aberdeen, AB15 8QH, UK, E-mail: iain.brown@hutton.ac.uk

\footnotetext{
${ }^{1}$ Corresponding author
} 
1 Exploring the linkages between multi-functional forestry goals and the legacy of spruce

2 plantations in Scotland

4 Abstract

6 This paper explores the ecosystem services associated with woodlands, as these are viewed by

7 individuals in Scotland, with the idea to reconcile objectives for multi-functionality with the

8 legacy of past forestry systems which were not designed with multi-functionality in mind.

9 Research follows a semi-qualitative route and applies the Q-method to identify and explain a

10 range of attitudes, among the general public and forestry associated stakeholders regarding

11 functional future of forestry in Scotland. Four distinctive groups of attitudes were identified and

12 key factors influencing the attitudinal diversity explained. Despite the uncovered attitudinal

13 heterogeneity, all groups of attitudes have strong emphasis on native woodland regeneration and

14 on improvement of aesthetic values of woodlands, but differ concerning afforestation. An

15 improved understanding of what people think provided indication of their recognition of

16 ecosystem services types and the trade-offs between these, as well as of opportunities available

17 and of factors that can hamper forestry development (e.g. concerning the aspiration of increasing

18 Scotland's forest cover to 25\%). Findings suggest that the Productivists position (for which the

19 economic objectives are important) remains strong in Scotland. Results (compared with those in

20 several other countries) demonstrate comparability between public and stakeholder perspectives

21 in support of the multi-functional forestry, and this has distinct policy relevance and implications

22 for decision-making.

23 Keywords: ecosystem services, woodlands, stakeholders, attitudinal diversity, Q-method 


\section{$24 \quad 1 . \quad$ Introduction}

25 Policy objectives for sustainable forestry have changed in recent decades to emphasize its

26 multiple benefits. These benefits are often established by comparison and as complements to

27 other land use systems, notably agriculture (Slee et al., 2015). However, the forestry sector

28 generally has relatively long time horizons associated with the time that trees take to become

29 established or reach maturity. Hence, the landscapes of today are still strongly influenced by

30 legacy decisions from the past and policy objectives still remain to be fully realized on the

31 ground. The forestry sector in many countries is therefore typically undergoing a process of

32 change, and a diversity of stakeholder attitudes may not always be consistent with policy

33 objectives. In this contribution, the dichotomy between the legacy of the past and objectives for a

34 sustainable future are investigated with regard to land use in Scotland and this may then be used

35 to identify implications for transition pathways towards genuine multi-functional forestry.

\section{$36 \quad 1.1$ Forestry in Scotland}

37 Scottish landscapes were deforested early and extensively (Fowler, 2002). The substantial area of

38 largely unbroken dense forests progressively disappeared under anthropogenic influence, with

39 only $4.5 \%$ of the land covered with trees at the lowest point (Smout et al., 2005). Deforestation

40 had occurred as a result of the forces related to economic growth and of a scant attention paid to

41 the environment (Nijnik and Mather, 2008). Deforestation was followed by tree-planting

42 initiatives especially in the $19^{\text {th }}$ century, when private planting of exotic species was widespread;

43 and in the $20^{\text {th }}$ century, by further planting of monoculture conifers by the state forestry authority,

44 with the primary policy objective to produce commercial timber (Nijnik and Slee, 2008). The

45 former policy of the creation of commercial plantations was justified for the reasons that: conifer

46 monocultures are more productive and easily managed; straight-edged plantations minimise 
47 fencing costs, which often make up half the establishment costs; large areas bring economies of 48 scale; and hardy pioneer species, such as Sitka spruce (Picea sitchenis), were a necessity for 49 establishing forest ecosystems on poorer quality lands (Warren, 2002).

50 In terms of the actual political and economic achievement, the afforestation programme has been

51 remarkably successful. The forest area in Scotland trebled during the 20th century. However, by

$522000,70 \%$ of the forest area was coniferous, with $47 \%$ of Sitka spruce. Much of wooded cover in

53 Scotland was established under political circumstances that no longer exist and for purposes that

54 are no longer relevant (Mather, 2003). In forestry, however, "the sins of the fathers...live for a

55 long time and the recent forest enlightenment will not bear visual fruit for many years to come"

56 (Lister-Kaye, 1995, p.61). Today's forests are a product of the past. Their share in percentage of

57 the land area in Scotland is ca. 17\% (FC, 2010); and conifer plantations largely of exotic species

58 (primarily of Sitka spruce) still dominate many landscapes, Figure 1 (Nijnik and Slee, 2008).

\section{$59 \quad$ Figure 1}

60 Much of the new Scottish woodland has been developed in remote locations, and forest culture, 61 as manifested in folklore, literature and art, has been relatively modest (Mather, 2003). Also, in

62 the past, people were not encouraged to visit woodlands, which were usually viewed as the

63 domain of private landowners, and there was a social as well as a geographical gulf between

64 people and forests (Mather et al., 2006).

65 It was only in the early 1990s that non-material values emerged as an important issue on the 66 policy arena (Wiersum, 1995). The Non-Binding Principle that forests should be sustainably 67 managed to meet social, economic, ecological, cultural and spiritual human needs of present and 68 future generations, has been influential (UNCED, 1992). Since then the objective of forestry in 69 Scotland has been shifting from its predominantly material (commodity) production towards 
70 multi-functionality (Nijnik and Mather, 2008). The relative societal weight of forestry and its

71 contribution to livelihoods have changed. Conifer tree-planting has also decreased (Figure 2).

\section{Figure 2}

73 There is an increasing interest by decision-makers in ecosystem management, small scale forestry

74 and adaptive forest management (Nijnik et al., 2008; Sarkki et al., 2015). Forestry policy actors,

75 uses and activities have changed. Multi-functionality is reflected in policies, both national

76 (Scottish Government, 2011) and international (MEA, 2005), with attention in research agendas

77 in Scotland given lately to multiple ecosystem services (Thomas et al., 2015). Existence of

78 forestry multi-functionality in Scotland is backed up by empirical evidence from institutional

79 analysis and public opinion surveys (Nijnik and Mather, 2006), and it is expressed in real terms

80 on the ground (Mather et al., 2006). Multi-functionality is seen as a strategy capable to meet

81 increasing private and public demand in modern societies (Schmithusen, 2007). In Scotland, the

82 concept of multi-functionality is seen as central to the national Land Use Strategy (Scottish

83 Government, 2011) which aims to deliver a more integrated approach linking land and people

84 and having 'the right tree in the right place' (Munoz-Rojas et al., 2015). An essential pillar of the

85 Strategy is woodland expansion with an aspiration to reach $25 \%$ cover by 2050.

\section{$86 \quad 1.2 \quad$ Models of multi-functionality}

87 Significant characteristics of multi-functionality are: (i) multiple commodity and non-commodity

88 outputs that are jointly produced; (ii) poorly functioning markets for public goods which

89 constitute some of the non-commodity outputs (Maier and Shobayashi, 2001). 'Joint', however,

90 gives rise to questions of scale, time and space. Should multi-functionality apply in the vertical

91 sense, with each field or forest stand fulfilling two or more functions (e.g. with reconciling

92 multiple benefits at landscape scale and designing forestry to deliver this), or can it be used to 
93 describe a pattern of diversity in which different units of land are dedicated to different

94 functions? The debate began in mid-20 ${ }^{\text {th }}$ century (e.g. Dana, 1943; Pearson, 1994), became

95 polarized, and was never resolved. Dana implied a 'vertical' interpretation of multi-functionality

96 while Pearson's view was of its 'horizontality', i.e. of effective multiple use of forest on the basis

97 on merely organized and coordinated specialization (Sedjo, 2004). The former view was

98 dominant in the last part of the $20^{\text {th }}$ century, arguably the origins of forest ecosystem

99 management. However, the latter also has its advocates (Vincent and Binkley, 1993).

100 Another challenge of multi-functionality in forestry originates from the fact that the joint 101 production (and consumption) of multiple ecosystem services (supporting, provisioning, 102 regulating and cultural/social, MAE, 2005) may result in conflicts between stakeholder interests.

103 Stakeholder interests are diverse in number, as is the range of forestry related stakeholders.

104 Therefore, a better understanding of stakeholder attitudes and perspectives is important for 105 informing the design of policies of various levels on the delivery of ecosystem services, and for 106 identifying future opportunities and management practices pertaining to forest multi107 functionality. It is also necessary to understand current forestry changes in practice and the extent 108 to which they manifest policy objectives, including goals for woodland expansion.

109 While the demand and supply of marketable forest commodities (e.g. timber) can be analysed by 110 economic models, with choices and resource allocation mediated by markets, social expectations, 111 preferences and needs for public goods require novel, and more pluralistic valuation methods, or 112 their combination (e.g. of analytical and participatory techniques by Nijnik and Mather, 2008; 113 participatory techniques and visualization tools by Miller et al., 2009, or Q-method combined 114 with aggregated ecological indexes, c.f. Nijnik et al., 2008). The literature provides strong 
115 arguments that stakeholder preferences for the social states of public goods should be determined

116 through non-market-oriented postulates, or revealed through mechanisms other than the market

117 (Kant, 2003). Thus, application of Q-method to understand the variety of subjective viewpoints

118 on an issue (briefly explained in Section 2) which avoids the challenge of questionable

119 attributions of pseudo-market values, is particularly useful in identifying potential conflicts (e.g.

120 between stakeholder interests) to avoid and manage them, or for assisting decision-makers with a

121 proper incorporation of public perceptions into the policy design.

122 Thus, the objective of this paper is to examine the heterogeneity of stakeholder attitudes towards

123 the services that forest ecosystems can provide and the trade-offs between these services. We

124 used the Q-method and carried out research in three phases. Phase 1 was on public attitudes

125 towards woodlands expansion in Scotland, with a particular attention given to Sitka spruce

126 forests. Phase 2 addressed stakeholder priorities for landscape changes and characteristics, and

127 the role of woodlands (both native and exotic, e.g. Sitka spruce) in Scottish countryside. Phase 3

128 covered stakeholder evaluation of multi-functional forestry, with analysing of trade-offs between

129 ecosystem services and comparison of the results across several countries in Europe. At each

130 research phase, heterogeneities of perspectives were identified through characterizations of

131 attitudinal groups and concise analyses that follow.

\section{2. Methodology and research framework}

\section{2.1. Briefly on the method-in-use}

134 The development of participation as a tool to assess values and attitudes is rooted in planning and

135 decision-making theory that considers public participation as a method, or a set of guidelines and 136 practices, by which there can be greater involvement of participants in specific activities in order 137 to accomplish research objectives or to inform policy (Miller et al., 2006). The range, number 
138 and type of participants are key characteristics of the participation process. These participants are

139 'stakeholders', as is any person, group or institution that has an interest (UKODA, 1995).

140 Awareness raising is important for stakeholder engagement (Scottish Government, 2015) the

141 main objective of which is to improve and facilitate the decision-making process, such as of

142 multi-functional forestry development. Therefore, because of forest policy relevance of this

143 research and the anthropocentric nature of the ecosystem services concept, we started empirical

144 work with identification of stakeholders to be interviewed.

146 Following van Asselt et al. (2001) who distinguish five types of participants considering public

147 decisions: (1) government and decision-makers; (2) citizens; (3) interest groups; (4) business

148 men; and (5) scientific experts, we came up with the list of key stakeholders regarding multi-

149 functional forestry. The participants included (1) forestry related decision-makers, first of all the

150 Forestry Commission, and forest owners and managers; (2) local people, as the primary forest

151 users; (3) forest and environmental NGOs; (4) forest based industries, and (5) scientific experts in

152 forestry and in ecosystem services of trees.

154 The Q-method allowed for a rather simple data set, because most of the data in this type of 155 analysis derives from how much information is implicit in each participant's Q-sort, i.e. the 156 formal model of each person understanding of the points of view at issue (Barry and Proops, 157 1999). Respondents were diverse in their social-economic backgrounds, but the number of actual 158 questionnaire participants was not large, with 86,30 and 66 respondents at each phase of the 159 research, correspondingly. Phase 1 (addressing the role of woodlands for the development of 160 countryside) reflected on public attitudes to woodlands, in Scotland. Respondents, therefore, 161 were randomly chosen from the public, and then, the selection was adjusted for background 
162 characteristics of respondents (gender, age, education, occupation, income, partnership status

163 etc.) to be almost equally spread among the categories suggested by van Asselt et al. (2001).

165 Phases 2 and 3 addressed the attitudes of forestry stakeholders. Therefore, only forestry related 166 stakeholders, falling under the van Asselt's et al. categories, were interviewed. At Phase 2 (to 167 assess stakeholders' opinions concerning landscape changes and components) 30 land use/

168 forestry stakeholders were approached. At Phase 3, we interviewed 66 stakeholders related to 169 forestry and multiple ecosystem services of trees. They included academics and those coming 170 from both the 'demand' or 'supply' sides of forestry. Further, we compared the results for 171 Scotland with those for the Netherlands, Poland, Romania and Sweden where matching research 172 was carried out.

174 The Q method (Brown, 1996) incorporates elements of behavioural studies into action research. It 175 combines qualitative and quantitative tools and starts with consultation with stakeholders to 176 identify research essentials. Statements are derived through a concourse analysis. Next, to 177 examine individual agreement/disagreement on a specific issue presented in statements, each 178 respondent is asked to rank each statement at a normal distribution sorting chart, i.e. a Likert 179 scale, generating a Q-sort. Then, each Q-sort, i.e. the formal model of each respondent's view 180 (i.e. his/her individual opinion about statements) is correlated with every other Q-sort, and their 181 inter-correlation matrix is factor-analyzed to find attitudinal clusters that exist (Brown, 1996). 182 Because these clusters are associated with respondents, Q factor analysis enables linking these 183 clusters of opinions to individual background characteristics of respondents. Thus, the use of this 184 method leads to identification of prevailing attitudinal typologies. The resulting factors, i.e. 185 typical Q-sorts, represent the attitudes people have, allowing us to explain the attitudinal 
186 heterogeneity and to improve understanding of why people have their perceptions. Key steps of a

187 Q-method research are shown in Figure 3.

188 Figure 3

189 Comprehensive information about this method and on its comparison with standard R-analysis is 190 now available in the literature (Adams and Proops, 2001; Nijnik et al., 2009).

\section{2.2. Research elements and flow}

192 As mentioned earlier, there were three phases in this Q-study. Three questionnaires (i.e. sets of 193 statements) were therefore designed in line with the research objectives. Statements were 194 designed through concourse analysis (from the Latin 'concursus', meaning 'running together') of 195 the full breadth of social discussions, surrounding the particular issue examined (Stephenson, 196 1978). Each of our three questionnaires consisted of 36 statements and 36 boxes in a normal 197 distribution sorting chart.

199 The following are shortened examples of Phase 1: "Native woodlands should be preserved 200 whatever the cost', 'We should be more self-sufficient in timber and plant fast growing trees',

201 'The rights of people to enjoy the countryside are more important than making profits from the 202 land', and' Planting trees to create jobs is more important than protecting wildlife and nature'. At 203 Phase 2, we used, for example, the following statements: 'New planting must be in tune with the 204 character of the landscape' and 'Beautiful landscape that is not being used for recreation is 205 essentially being wasted'. Phase 3 statements included, as follows: 'After clear cutting, the

206 ecosystem will never return to its previous state', 'Many wild species require an uninterrupted 207 forest for nesting', 'Subsequent growth and forest plantation are never as good for ecosystems, as 208 old growth', 'Forest is made wealthy through clear cutting', 'Hunting is stabilising the 209 population, and is good for forest', 'The majority of wildlife species have enough environmental 
210 niches for living'. Each respondent distributed the statements across the Likert chart, on a scale

211 ranging from +5 through -5 , based on their agreement/disagreement with the statements (where

$212+5$ indicated 'complete agreement', and -5 indicated 'complete disagreement', with zero showing

213 a neutral attitude to the statement).

214 After the respondents had ranked the statements, the output data were assessed, using the

215 sequential application of multiple regression and factor analysis. Factor analysis created a few

216 new uncorrelated choice variables - a set of factors, i.e. groups of attitudes which are called

217 typical Q-sorts - that have captured the common essence of the several individual Q-sorts

218 (Brown, 1996). The resulting 'factors' represent the heterogeneity of attitudes for use in

219 explaining the diversity of opinions expressed, and a basis for interpretation of why people hold

220 their opinions. In our research, each statement in the Q-sample was also scored for each factor,

221 enabling us to analyse the statements' significance to each factor. The final steps comprised

222 interpretation of the social discourses uncovered; contrasting the value outputs with the socio-

223 economic background of respondents (gender, age, education, occupation, income, partnership

224 status, etc) and verification, and communication the results with/to stakeholders who contributed

225 to the surveys.

$226 \quad 3 . \quad$ Results

\section{$227 \quad 3.1 \quad$ Results of Q-analysis of public attitudes towards woodland expansion}

228 Phase 1 findings show public support to woodlands expansion, as offering a range of benefits to

229 the Scottish people and the environment. Despite evidence of the importance of enlarging the

230 area of wooded cover in this country, the research came up with results showing a diversity of

231 public attitudes towards afforestation. Three predominant attitudinal groups, with two subgroups

232 in each group (six attitudinal groups in total) were distinguished (explaining $73 \%$ of the 
233 underlying variation in responses). The first group named as 'productivists' is highly distinctive

234 and explains $27 \%$ of the variation. It means that part of the public in Scotland considers the

235 creation of new jobs in remote rural areas as a very important policy objective. The legacy of

236 Sitka spruce could be regarded as something quite positive in this setting; and looking at

237 woodlands expansion through the eyes of Productivists, we could find some evidence in support

238 of plantation forestry as having its prospering near future in this country. Productivists place a

239 clear emphasis on woodland expansion, and consider the social and economic aspects of forestry

240 development as crucial. The attitudinal group consists of two subgroups comprised of

241 respondents with different degrees of support given to productivist forestry. Those belonging to

242 the first subgroup are more extreme and focus primarily on the enlargement of the wealth of rural

243 communities and on the increase of income. In contrast, those belonging to the second subgroup

244 are oriented towards balancing socio-economic objectives of forestry development with

245 environmental considerations.

246 The second major reason for public support of the policy for expansion of woodlands

247 distinguished in this research was that people recognise the desirability of improving rural

248 landscapes. A number of people, belonging to this attitudinal group (which, in line with the

249 prevailing preferences/perceptions, was called Recreationists), were preoccupied with aesthetic

250 values of landscapes and people's rights to enjoy landscape beauty. Some respondents

251 characterized as Recreationists, in addition, were interested in socio-economic aspects of

252 landscape changes, e.g. in attracting of tourists to the remote areas. There is also a distinctive

253 attitudinal group that recognises the intrinsic value of nature and is primarily ecologically

254 oriented. We named this group Conservationists. Whilst other groups do not have strong

255 prejudice against the enlargement of wooded area at the expense of non-native species (e.g. Sitka 
256 spruce), Conservationists support extensive native woodlands regeneration and biodiversity 257 conservation. There are two subgroups in this group: with more extreme and less extreme 258 attitudes with regard to their appreciation of environmental and cultural values of nature.

259 Findings allowed us to argue that people consider an increase in the relative level of subsidies to 260 forestry to be important for satisfying the priority objectives of woodlands development. 261 Heterogeneity of public attitudes appeared to be dependent on age and living conditions and still 262 more on stakeholder competencies, e.g. work experience, occupation and education (and is not 263 dependent, for instance, on gender). For example, farmers interviewed during this phase of the 264 research primarily appeared to belong to Group 1 (Extreme Productivists), while scientists and 265 researchers could largely be categorised as Recreationists.

266 A general observation from Phase 1 of our research is that people have diverse opinions about

267 woodlands expansion in Scotland. There is a distinct group of respondents who are in favour of 268 native woodlands regeneration and biodiversity conservation. The other dominant attitudinal 269 group is preoccupied with rural landscapes and/or with opportunities they could provide to local 270 people, to recreationists/tourists and rural economy. Also, socio-economic problems in remote 271 rural areas are of primary concern to those respondents, whom accordingly, we named as

272 Productivists. These people consider timber production central, and therefore would not really

273 mind having forests dominated by Sitka spruce. Importantly, despite the diversity of public

274 attitudes identified, there is a general understanding of the desirability of forestry development in

275 Scotland, and of proper integration of woodlands in rural landscapes, i.e. "getting the right trees

276 in the right places for the right reasons" (Warren, 2002; Munoz-Rojas, 2015).

\section{$277 \quad 3.2 \quad$ Results of stakeholder evaluation of landscape characteristics}


278 The results of Phase 2 of the research shows that the attitudinal diversity of forestry related

279 stakeholders in Scotland falls into four major groups (Table 1)

280 Table 1

281 Such heterogeneity of attitudes likely suggests the following priorities for possible directions and

282 of the efforts required for landscape changes, as these are seen by our respondents:

283 - Group 1: policy and management initiatives to address both, socio-economic and ecological

284 objectives of landscape changes in rural areas, with an increase of subsidies to farmers/land

285 owners to support productive forestry but to balance it with improved landscape management.

286 - Group 2: allocation of extra funds for nature protection and biodiversity conservation, for

287 improvement of landscape visual characteristics, and socio-economic development.

288 - Group 3: enhancement of farming and urban-rural industrial activities with the development of

289 infrastructure.

290 - Group 4: promotion of economic and social development, including the development of tourism

291 and recreation in remote rural areas.

292 Comparing the Phase 2 results with the Phase 1 findings, we could argue that the attitudinal stand

293 of Group 2 respondents comes close to the position of Conservationists and Recreationists. We

294 can also suggest that forestry related stakeholders are likely even more in favour of 'production'

295 forestry than is the general public, and that the Productivists' position (for which the economic

296 objectives are crucial, and therefore, Sitka spruce would remain a predominant species) is

297 generally strong.

299 The results also indicate that stakeholder valuation of landscapes is strongly influenced by the 300 presence of woodlands and landscape characteristics such as landscape capacity; diversity; 
301 resourcefulness of landscape (Valk et al., 2010); visual accessibility; spatial continuity; temporal 302 continuity; environmental health and vitality; diversity of flora and fauna; aesthetic values of

303 landscapes; and profitability of land use management (Nijnik et al., 2009). For example, Group 2

304 identified the following as important characteristics: open access to the countryside, with 305 properly designed and managed access routes; landscape visual accessibility; spatial continuity;

306 landscape diversity, with high variety of components and their resourcefulness; the diversity of

307 flora and fauna; and high aesthetic values of landscape. Overall, our findings suggest that the

308 most preferred features of landscapes in Scotland are physical accessibility (e.g. availability of

309 access routes), visual accessibility, and spatial continuity of landscapes (Figure 4).

$310 \quad$ Figure 4

\section{$311 \quad 3.3 \quad$ Results of stakeholder evaluation of ecosystem services and forest multi-functionality}

312 Five groups of attitudes were distinguished on the basis of similarities/differences in participants'

313 responses to the Phase 3 questionnaire when multi-functional forestry and ecosystem services

314 issues were addressed. Of the five groups, three were major groups (and in concordance with the

315 Phase 1 results of our study) associated with the Conservationists, Productivists and

316 Recreationists types of attitudes. Those with the Conservationists attitudes fell into two groups

317 which were recognised as Extreme (Group 1) and Moderate Conservationists (Group 4), while

318 Productivists comprised of Extreme and Moderate Productivists (Groups 3 and 5).

319 Conservationists (by definition) give their priority to biodiversity conservation over more

320 traditional forestry practices (e.g. of Sitka spruce plantations). Extreme Conservationists (Group

321 1) would rather not allow any disturbance to habitats (e.g. by closing roads and prohibiting

322 logging operations). Moderate Conservationists (Group 4) favour multi-functional forestry, and

323 support nature conservation equally with forest provisioning services. The major preference of

324 Recreationists (Group 2) is given to the regeneration of forest to provide social and economic 
325 benefits. They support recreation in forest, and suggest that hunting and fishing are necessary to

326 maintain the quality of ecosystems and a wider countryside (Figure 5).

327 Figure 5

328 Productivists (Groups 3 and 5) prioritize the provisioning services above all others. Moderate

329 Productivists are keen to maintain a balance between timber production and other ecosystem

330 services. They support grazing and farming in woodlands, and care for the quality of forest

331 stands, as well as of old growth forests, and of hardwood and native species, whilst maintaining

332 that forests remain a source of timber. They consider forest tourism as socially beneficial.

333 Extreme Productivists consider above all the importance of maintaining forest as a source of

334 wood and endorse the associated Sitka spruce plantations. They recognise the need for clear-

335 cutting operations. This group supports the presence of leisure/recreation facilities in forests used

336 for recreation (i.e. kind of 'horizontal' multi-functionality), considers forestry and farming as

337 separate businesses, but tends to deny the legitimacy of additional nature conservation measures

338 and their added financial support (arguing that "the majority of wildlife species have enough

339 environmental niches for living").

340 An important observation from Phase 3 research is that despite their distinct views, all attitudinal

341 groups support the regeneration of forests and the resilience of ecosystems. Also, regulating and

342 supporting services are endorsed by all, with the exception of one group which was therefore

343 labelled as Extreme Productivists. All groups, except Group 4, named as Moderate

344 Conservationists, encourage the development of recreation, and hunting and fishing opportunities

345 in forests, and consider cultural services of forest as important. Enhancement of provisioning

346 services and the necessity to increase the wealth of local communities is supported by all

347 attitudinal groups, with the exception of Extreme Conservationists. Despite the attitudinal 
348 differences, the two groups named as Moderate Conservationists and Moderate Productivists

349 appeared to be close in their understanding of trade-offs between various ecosystem services and

350 the balancing of often competing objectives of forest multi-functionality.

\section{$351 \quad 3.4 \quad$ Cross-country comparison of stakeholder evaluation of ecosystem services}

352 The results of the Phase 3 survey also provided information on the differences/similarities in 353 opinions of stakeholders coming from Scotland as compared with those in several other countries

354 representing the diversity of natural and socio-economic conditions of forestry development.

355 There is some indication that respondents from Scotland and Sweden have a wider outlook on 356 sustainable resource development and forest provisioning services (also observed in Romania).

357 Farming is seen as an integral part of landscapes. There is support for old growth and hardwood 358 forests; and the development of a modern infrastructure is largely encouraged (Figure 6).

\section{$359 \quad$ Figure 6}

360 The low representation of Recreationists in Scotland can be explained by a legacy of 361 monoculture forest plantations. However, as evident from Phase 2 of our research, stakeholder 362 attention is given to enhancement of the aesthetic component of woodlands in landscapes in 363 support of their potential role in tourism. Respondents from Sweden are distributed evenly across

364 the attitudinal groups which may indicate the importance of forestry for both timber production 365 and provision of other ecosystem services. In the Netherlands, where the economic role of 366 forestry is insignificant, Extreme Productivists are not represented. Respondents from Poland 367 have quite radical nature conservation views, which also allow for recreational opportunities. The 368 Romanians have moderate nature protection motivations, with support to forest regeneration.

369 The heterogeneity of attitudes across countries could be explained by the diverse institutional 370 environments, competences, and capacities, influencing stakeholder preoccupation with multiple 
371 opportunities, problems and consequences of forest management and use (Nijnik et al., 2010).

372 Stakeholder attitudes towards multi-functional forests and to the provision of ecosystem services

373 seem to be dependent upon the socio-economic, political and historical preconditions, cultural

374 standards and ethical principles operating in each of the EU states. Nonetheless, respondents from

375 all countries are represented in the group of Extreme Conservationists. Overall, results provide a

376 better understanding of the diversity of existing attitudes towards woodlands, with respect to

377 major environmental and visual components of landscapes and in view of implications that

378 forests can have for the environment and people.

$379 \quad 4 . \quad$ Conclusions

380 Q-method has proved through this research to be a useful tool capable of identifying and 381 explaining attitudinal heterogeneity in order to balance stakeholder interests, where possible; to 382 identify potential conflicts in order to assist in avoiding and/or managing them, and likely to 383 assist decision-makers with the incorporation of existing perceptions into policy design. The use 384 of Q-method enabled us to reveal and assess attitudes and perspectives from the standpoint of the 385 persons being observed. It helped us to identify respondents' preferences, to analyse criteria 386 relating to their perspectives and to suggest factors influencing attitudinal diversity.

388 Research provided empirical evidence of stakeholders' understanding that sustainable multi389 functional forestry is the direction in which to go, so as to multiply benefits to society and the 390 environment. Prevailing attitudes identified in this paper, however, appear to be diverse. For 391 example, some people in Scotland (Extreme Conservationists) strongly support native woodland 392 regeneration. Others (in particular those classified as Extreme Productivists) consider above all 393 the importance of maintaining forest as a source of wood. They would not mind a dominance of

394 Sitka spruce in rural landscapes. The purpose of this research was to show the diversity of 
395 attitudes and perceptions that exist, yet not reconcile the differences. Further research is

396 recommended to show whether attitudes vary over space in Scotland and whether some regions

397 tolerate Sitka spruce more than others.

399 Despite the heterogeneity of attitudes, public support of proper integration of woodlands in

400 Scottish countryside is noticeable. The thrust of multi-functional forestry is supported by our

401 results, and forest multi-functionality in turn, is aligned with international trends and agreements

402 relating to the role of forests in rural landscapes. The overall conclusion is that although some

403 people in Scotland are in favour of native woodlands conservation and their extensive

404 regeneration, whilst others are more concerned with socio-economic aspects of forestry

405 development, e.g. with new employment opportunities, there is likely an agreement across

406 various categories (attitudinal groups) on the necessity of multi-functional forestry development.

408 The mix of attitudinal groups implies their recognition of ecosystem services types and the trade-

409 offs between those (Figure 5). Moreover, alongside with the pressures to manage Scottish

410 woodlands multi-functionally and sustainably, there is a need to recognise the very considerable

411 challenges raised by global warming and by the need to develop forestry strategies which

412 confront those challenges. It seems highly probably that the creation of new forests, and

413 particularly of Sitka spruce, will play a significant role in sequestering carbon (cf. Nijnik et al.,

414 2012) and that the mix between native woodlands and exotic species may need to be reconsidered

415 in the light of these compelling new demands on woodland resources (Slee et al., 2012).

416 Our findings provide additional evidence that in Scotland, the Productivist position proves to be 417 rather strong, and a new phase in forest multi-functionality could mean a further shift towards 
418 commercialisation of forestry, including for carbon and recreation. Also, through the level of 419 importance accorded by the people to the integration of woodlands in Scottish landscapes, the 420 research has demonstrated comparability between public and expert preferences in support of the 421 multi-functional future of forestry. This comparability between public and expert preferences is 422 important for decision-making, and stakeholder attitudes and preferences concerning various 423 ecological, socio-economic and aesthetic aspects of landscape changes have policy relevance in 424 terms of their matter and scale. 


\section{Acknowledgement:}

368 This paper is part of the thematic research of Scottish Government Strategic Research

369 Programme. We are grateful to Professor David Miller and Professor Bill Slee for helpful

370 comments on an earlier draft. Our thanks go to the respondents participating in the survey and to

371 anonymous reviewers of this paper.

372 


\section{References:}

Adams, H. and Proops, J. 2001 Social Discourse and Environmental Policy. An Application of Q Methodology, Cheltenham: Edward Elgar.

Barry, J. and Proops, J. 1999 Seeking sustainability discourses with Q methodology. Ecol Econ 28: $337-345$.

Brown, S. 1996 Q methodology and qualitative research. J Qualit. Health Research 6: 561-567.

Dana, S.T. 1943 Multiple use, biology and economics. J of Forestry 41: 625-627.

Forestry Commission (FC) 2010 Forestry Facts and Figures. Edinburgh: Forestry Commission.

Fowler, F. 2002 Survey Research Method. Sage Publications.

Kant, S. 2003 Extending the boundaries of forest economics. For Policy \& Econ 5: 39-56.

Lister-Kaye, J. 1995 Native pinewoods and sustainable development of the Highlands, in: Aldhous, J. R. (eds), Our Pinewood Heritage. FC/RSPB/SNH: 60-3.

Maier, L. and Shobayashi, M. 2001 Multifunctionality: Towards the analytical framework. OECD, Paris, France.

Mather, A. 2003 The future, in: Smout, T. C. (ed.), People and woods in Scotland: a history. Edinburgh Uni Press.

Mather, A., Hill, G. and Nijnik, M. 2006 Post-productivism and rural land use: cul de sac or challenge for theorization? J Rural Studies 22: 441-455.

MEA 2005 Millennium Ecosystem Assessment Synthesis Report. March 2005. http://www.millenniumassessment.org/en/index.aspx [accessed 28 September 2015].

Miller, D.R., Vogt, N., Nijnik, M., Brondizio, E. and Fiorini, S. 2009 Integrating analytical and participatory techniques for planning the sustainable use of land resources and landscapes. In: 
S. Geerteman and J. Stillwell (eds.) Plan Support Systems: Best Practises and New Methods, Springer Publs.

Miller D, Morrice J., Anderson, L., Durozard, E., Fidalgo, B., Fry, G., Gaspar, J., Gibon, A., Hassan, R., Hislop, M., Horne, P., Huet, B., Ladet, S., Lange, E., Leandro, N., Messager, P., Mottet, A., Nijnik, M., Ode, A., Pascoa, F., Pinto, L., Quine, C., Schroth, O., Schwarz, G., Shepherd, N., Sundli Tveit, M., Vitry, A., Watts, K., Wissen, U. 2006 Visualisation Tools for Public Participation in the Management of Landscape Change. Project Report Visulands, EC. Munoz-Rojas J, Nijnik M, Puente M G, Garcia F C 2015. The right trees in the right places? Synergies and conflicts in the use of policy and planning instruments for implementing forest and woodland corridors and networks in Scotland, For Policy \& Econ 57, August: 47-64, doi:10.1016/j.forpol.2015.05.002

Nijnik, M., Nijnik, A., Lundin, L., Staszewski,T. and Postolache, C. 2010 Stakeholder attitudes to multi-functional forests in Europe. Forests, Trees \& Livelihoods 19: 341-358.

Nijnik, M., Zahvoyska, L., Nijnik, A. and Ode, A. 2008 Public evaluation of landscape content and change. Land Use Policy 26: 77-86.

Nijnik, M. and Mather, A. 2009 Analysing public preferences for woodland development in rural landscapes in Scotland. Landscape and Urban Planning 86: 267-275.

Nijnik, M. and Mather, A. 2006 Analysing institutions and public perspectives to identify the future of British forests. In Reynolds, K.M., US DA Forest Service (eds): Sustainable Forestry in Theory and Practice: From Monitoring and Modelling to Knowledge Management and Policy Science, CABI Publs, pp. 171-188.

Nijnik, M. and Slee, B. 2008 Towards sustainable development of Scottish woodlands. In T.J. Chmielewski (eds): Nature Conservation Management: from Idea to Practical Results. PWZN Print, Lublin, Poland. Pp113-132. ISBN: 83-87414-98-0. 
Pearson, P. 1994 Energy, Externalities and Environmental Quality: Will Development Cure the Ills it Creates? Energy Studies Review 6(3):199-216.

Sarkki S, Ficko A, Grunewald K, Nijnik M 2015. Benefits from and threats to European treeline ecosystem services: An exploratory study of stakeholders and governance. Regional Environmental Change. Volume 15 (4), http://dx.doi.org/10.1007/s10113-015-0812-3

Schmithüsen, F. 2007 Multifunctional forestry practices as a land use strategy to meet increasing private and public demands in modern societies. J Forest Science 53(6): 290-298.

Scottish Government, 2015. Land Use Strategy Progress Statement http://www.gov.scot/ Resource/0047/00478779.pdf, - 34 pages [accessed 28 September 2015].

Sedjo, R. A. 2004 Transgenic trees and trade problems on the horizon. Resources 155: 9-13.

Slee, B., Feliciano, D., Nijnik, M. and Pajot, G. 2012 The scope of the land-based sector to mitigate climate change in North-east Scotland: opportunities and challenges with particular reference to the role of forests. Int. J. Environ. \& Sust Develop 11( 3): 274-292.

Slee B., Brown I., Donnelly D., Godon I.J., Matthews K., Towers W. 2014. The 'squeezed middle': Identifying and addressing conflicting demands on intermediate quality farmland in Scotland. Land Use Policy 41 (November): 206-216.

Smout, T., MacDonald, A. and Watson, F. 2005 A history of the native woodlands of Scotland. Edinburgh Univ. Press, pp. 1500-1920.

Stephenson, W. 1978 Concourse theory of communication. Communication 3: 21-40.

Thomas Haydn J.D., Paterson J.S., Metzger M. J. and Sing L. 2015 Towards a research agenda for woodland expansion in Scotland. For Ecology \& Management 349(1)August: 149-161

UKODA 1995 UK Overseas Development Administration, http://www.globenet.org/preceup/ pages/fr/chapitre/etatlieu/acteurs/f/o.htm [accessed 28 September 2015]

UNCED 1992 Agenda 21, Chapter 37, par 1, UNCED, Rio, Brazil. 
Warren, C. 2002 Managing Scotland's environment. University Press, Edinburgh.

Wiersum, K. F. 1995200 years of sustainability in forestry: lessons from history. Environ Management 19(3): 321-329.

Valk, A.J.J. van der; Bloemers, J.H.F.; Kars, H.; Wijnen, M. 2010. The Cultural Landscape and Heritage Paradox. Scientific book or proceedings. Amsterdam University Press, Landscape \& Heritage Studies - 744 pp.

van Asselt, B.A., Mellors, J., Rijkens-Klomp, N., Greeuw, S.C., Molendijk, K.G., Beers, P.J., and van Notten, P. 2001 Building blocks for participation in integrated assessment: a review of participatory methods. Maastricht, Intern Centre for Integrated Studies (ICIS).

Vincent, J. R. and Binkley, C. S. 1993 Efficient multiple-use forestry may require land-use specialization. Land Economics 69: 370-376. 
Table 1: Heterogeneity of stakeholder attitudes, with four attitudinal groups (i.e. factors) identified, as presented in the matrix of factor loadings, with $X$ indicating a defining sort.

\begin{tabular}{lcccc}
\hline QSORT & 1 & 2 & 3 & 4 \\
\hline 1 & 0.0468 & -0.1641 & $0.8657 \mathrm{X}$ & 0.0114 \\
2 & 0.1081 & $0.8124 \mathrm{X}$ & -0.1080 & 0.0396 \\
3 & 0.2210 & $0.6866 \mathrm{X}$ & $-0.4959 \mathrm{X}$ & 0.0343 \\
4 & -0.0115 & 0.2001 & $0.8399 \mathrm{X}$ & 0.1761 \\
5 & -0.0654 & $0.8121 \mathrm{X}$ & -0.1006 & 0.2682 \\
6 & 0.0475 & $0.6876 \mathrm{X}$ & 0.3566 & -0.1492 \\
7 & 0.1877 & 0.0489 & $0.7240 \mathrm{X}$ & -0.0206 \\
8 & -0.0930 & -0.1808 & $0.7930 \mathrm{X}$ & $0.3538 \mathrm{X}$ \\
9 & 0.0915 & $0.6505 \mathrm{X}$ & -0.2551 & -0.0338 \\
10 & 0.1495 & 0.5868 & 0.5447 & -0.2914 \\
11 & -0.0188 & $0.5023 \mathrm{X}$ & $-0.6246 \mathrm{X}$ & -0.0417 \\
12 & -0.2365 & $0.6560 \mathrm{X}$ & 0.1259 & 0.0408 \\
13 & $0.6671 \mathrm{X}$ & 0.1888 & -0.0104 & 0.3221 \\
14 & $0.7053 \mathrm{X}$ & 0.1480 & 0.1535 & 0.1129 \\
15 & $0.5527 \mathrm{X}$ & -0.0384 & 0.1153 & 0.3758 \\
16 & $0.7809 \mathrm{X}$ & 0.3070 & -0.0606 & -0.0186 \\
17 & $0.7182 \mathrm{X}$ & 0.0808 & -0.0317 & $0.5172 \mathrm{X}$ \\
18 & $0.7952 \mathrm{X}$ & 0.0602 & 0.1948 & $0.3452 \mathrm{X}$ \\
19 & $0.7914 \mathrm{X}$ & 0.1629 & 0.1668 & 0.1506 \\
20 & $0.6900 \mathrm{X}$ & -0.0654 & 0.0105 & -0.1270 \\
21 & $0.6822 \mathrm{X}$ & -0.1744 & -0.1283 & -0.0029 \\
22 & $0.7750 \mathrm{X}$ & 0.1379 & -0.0103 & -0.2648 \\
23 & 0.2197 & -0.0332 & 0.1939 & $0.7281 \mathrm{X}$ \\
24 & 0.3140 & 0.2122 & $-0.5270 \mathrm{X}$ & 0.0166 \\
25 & $0.6476 \mathrm{X}$ & 0.3917 & -0.1537 & 0.0146 \\
26 & $0.7412 \mathrm{X}$ & -0.1284 & -0.3285 & 0.0273 \\
27 & 0.4048 & $0.6872 \mathrm{X}$ & -0.1478 & -0.2372 \\
28 & 0.2448 & 0.7442 & -0.0420 & -0.0205 \\
& & & & \\
\hline$\%$ expl.Var & 24 & 19 & & 16 \\
\hline
\end{tabular}

[1] An individual's loading on a factor is a correlation coefficient indicating the extent to which each of the 28 individual Q-sorts (i.e. the formal model of each of the 28 interviewed persons' understanding of the points of view at issue) is similar/dissimilar to each of the four composite factor arrays. A positive loading indicates that the respondent shares subjectivity with others on that factor, whilst negative is a sign of rejection of the factor's perspective.

[2] Dominating indicators are those with factor loadings $\geq 0.5$ or $\leq-0.5$.

[3] \% explanatory variation means that, when all Q-sorts are considered, the first factor explains $24 \%$ of the variation; the second factor explains $19 \%$ of the variation and so on. 


\section{Figure captions}

Figure 1. Conifer woodland in Scotland as seen at

http://www.macaulay.ac.uk/explorescotland/lcs_sc_woodland3.htm

Figure 2. Conifer planting in Scotland

Forestry Commission, 2015 as seen at http://www.forestry.gov.uk/

Figure 3. Sequencing of steps in a Q-study

Figure 4. Most preferable characteristics of Scottish landscapes as identified from the Qanalysis of stakeholder attitudes

Figure 5. Heterogeneity of stakeholder preferences with regard to forest ecosystem services and the trade-offs, as identified by the Q-analysis

Figure 6. Distribution of the groups within each country respondents 


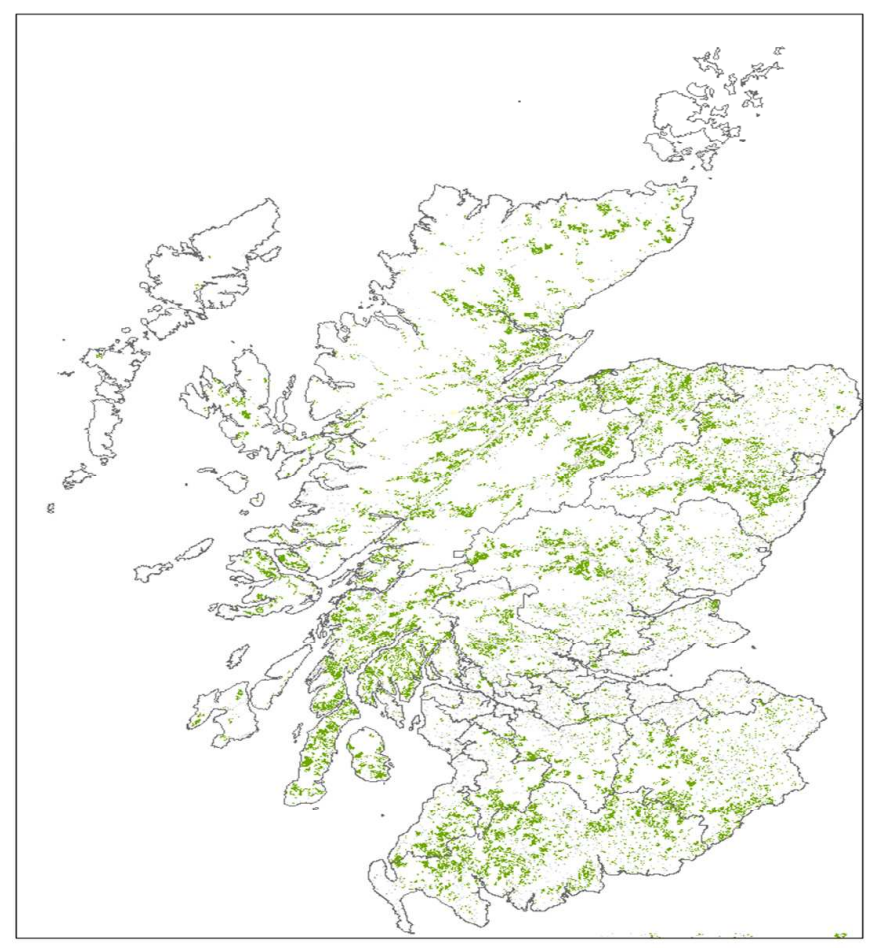

Figure 1. Conifer woodland in Scotland, as seen at http://www.macaulay.ac.uk/ explorescotland/lcs_sc_woodland3.htm 


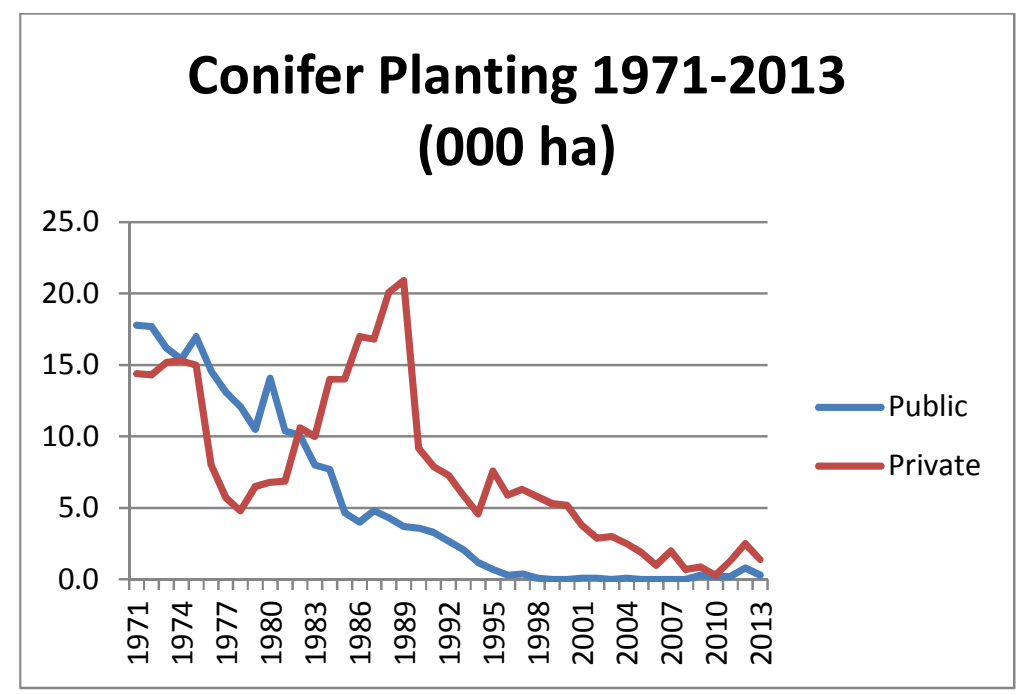

Figure 2. Conifer planting in Scotland

Based on Forestry Commission http://www.forestry.gov.uk/ 2015 data 


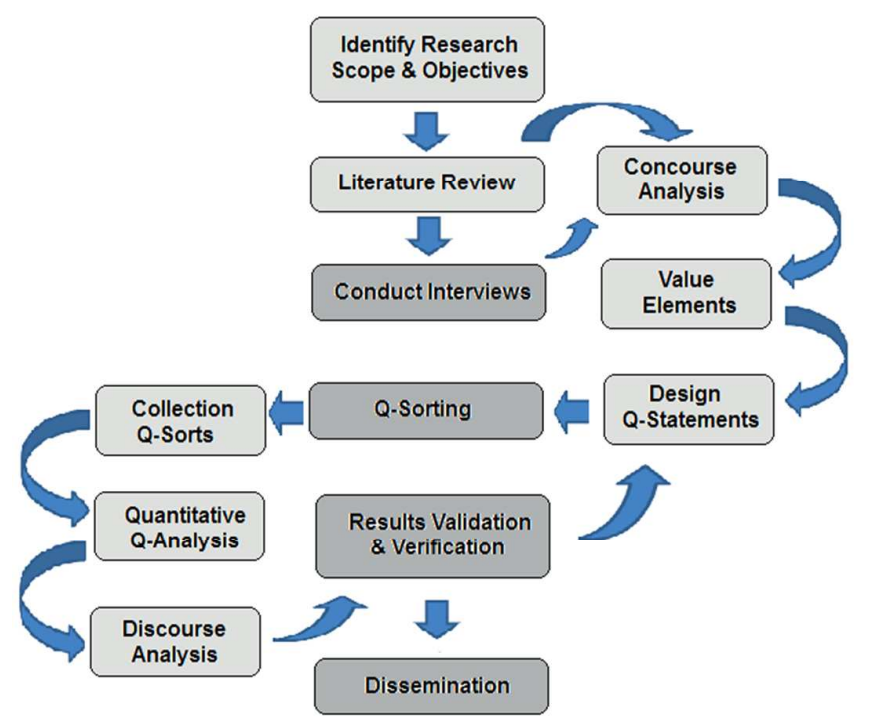

Figure 3. Sequencing of steps in a Q-study 


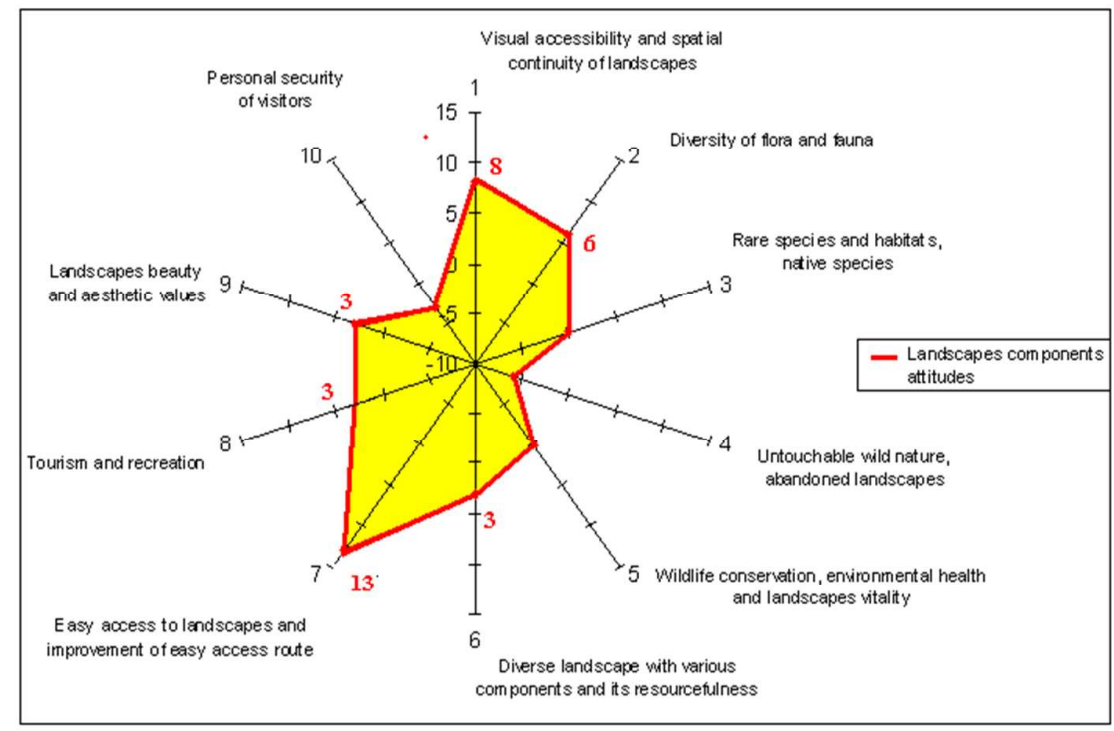

Figure 4. Most preferable characteristics of Scottish landscapes as identified from the Qanalysis of stakeholder attitudes 


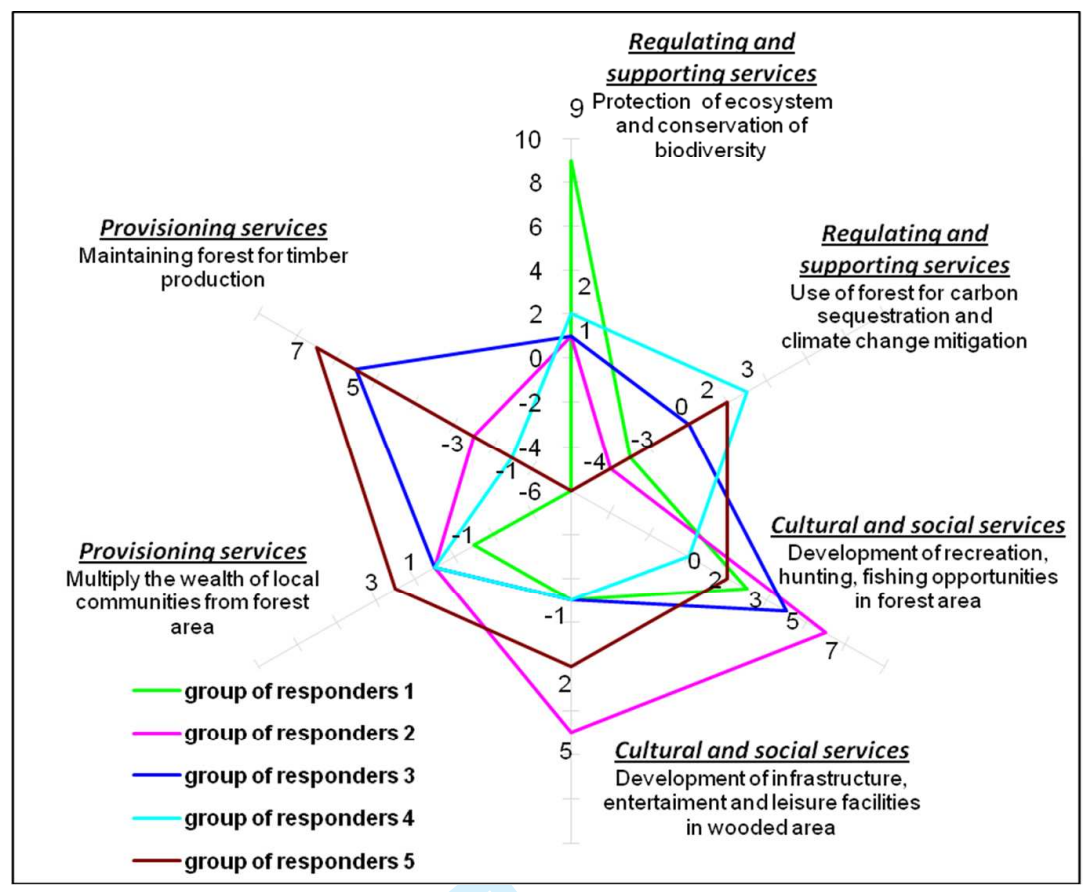

Figure 5. Heterogeneity of stakeholder preferences with regard to forest ecosystem services and the trade-offs, as identified by the Q-analysis 


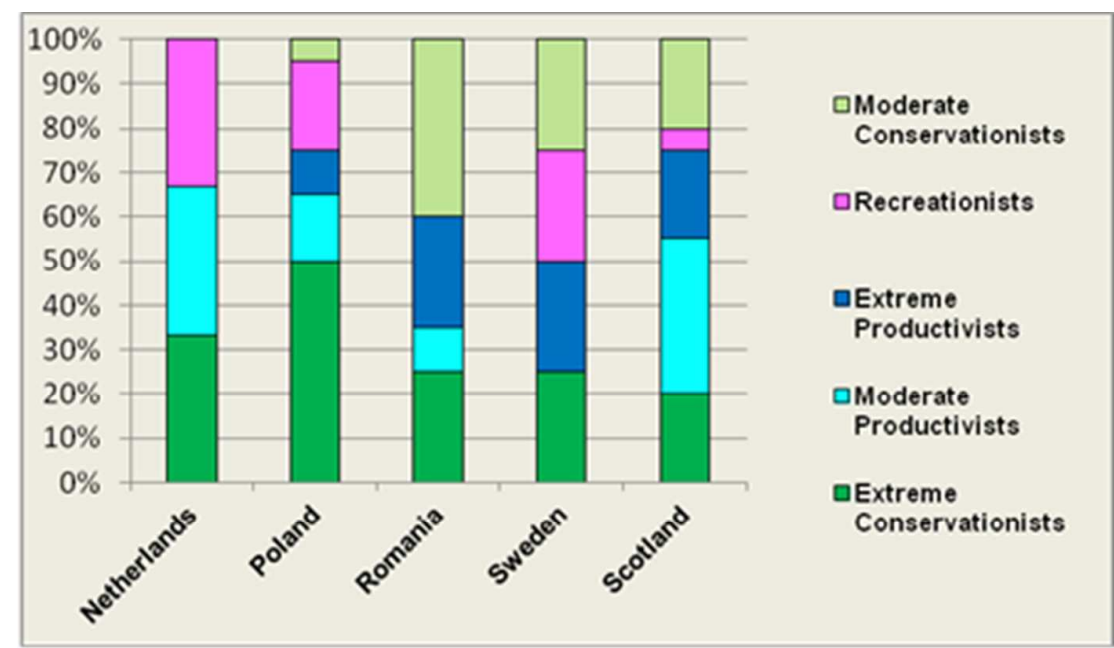

Figure 6. Distribution of the groups within each country respondents

Note: Each column totals to $100 \%$, showing the percentage of respondents which belong to different attitudinal groups in each country. 